\title{
A SIMULATION STUDY OF MUTUAL INFLUENCES OF ENGINEERING CHANGE MANAGEMENT PROCESS AND NEW PRODUCT DEVELOPMENT PROCESS
}

\author{
Weilin Li \\ Young B. Moon \\ 223 Link Hall \\ L.C. Smith College of Engineering \& Computer Science \\ Syracuse University \\ Syracuse, NY 13244, USA
}

\begin{abstract}
This paper presents a simulation model for assessing the mutual impacts of Engineering Change Management (ECM) process and New Product Development (NPD) process on each other. The discrete-event simulation model incorporates ECM into an NPD environment by allowing Engineering Changes (EC) to compete for limited resources with regular NPD activities. The goal is to examine how the relative size and frequency of NPD as well as ECM, NPD process structure (in terms of overlapping and departmental interaction), and the operational policy of resource using priority that one organization employs affect lead time and productivity of both NPD and ECM. Decision-making suggestions considering EC impacts are drawn from an overall enterprise system-level perspective based on the simulation results.
\end{abstract}

\section{INTRODUCTION}

New Product Development (NPD) refers to a complete process from idea generation, through product design, manufacturing, and bringing a new product to the market. It is a whole process beginning with the perception of a market opportunity and ending in production. There are general characteristics of NPD that are important to this research. First, typical companies launch their new products according to a relatively fixed schedule. NPD projects are generally well-planned in advance in terms of task schedule, stage gate dates and duration, resource allocation, performance measurement, and financial justification. As a result, a product development company typically runs multiple NPD projects in different design and development stages at the same time. Second, though scarce engineering capacity has always been a challenge faced by most organizations, resource commitment to an NPD project is relatively stable. That is, there are certain amounts of resources to be dedicated to each NPD project as stated by the proposed resource planning. Third, despite the above-mentioned predetermined side of NPD process, "iteration is a fundamental characteristic of complex design projects" (Cho and Eppinger 2005), which in turn causes significant departure from the initial planning, consuming more time and resources than expected, and may even lead to the failure of an NPD project. Fourth, despite the fact that the NPD process tends to become more and more complex, which is attributable to the increasing volume of information involved, some general repeatable structure can be discerned since "design is something of an art but with many consistent patterns" (Browning and Ramasesh 2007).

Engineering Change Management (ECM), on the other hand, refers to a collection of procedures, tools, and guidelines for handling modifications and changes to a product that has been released to the market (Terwiesch and Loch 1999, Bhuiyan and Thomson 2006). Unlike the iteration within the NPD process, an engineering change can be considered as the rework after production. It occurs in far more random pattern compared with regular NPD projects. The amount of time and effort required for each ECM also varies from case to case. Simple changes to the manufacturing specifications of a product component may just need a few days while some changes will cause unexpected downstream change propagation and result in significant resource consumption and a long overall EC processing time. Typically, ECM doesn't have its own separate resources. It shares the same pool of engineering resources with the ongoing NPD projects. That is, if there is no spare resource available when an Engineering Change Request (ECR) is made, the ECM process has to compete for the resources that have already assigned to regular NPD activities.

In reality, an EC is a norm rather than an exception in any typical product development firm. Consequently, ECM is a major competitive component in product design and development process that should not be neglected. It plays a critical role in finally realizing actual profits from new product development efforts. Companies benefit from ECM by correcting design faults, solving detected safety or functionality errors, correcting manufacturability problems, reflecting customers' require- 


\section{Li and Moon}

ments, and incorporating technology improvements (Balakrishnan and Chakravarty 1996). On the other hand, ECM consumes considerable amount of resources, which in turn affects the lead time and productivity of regular NPD projects significantly. It also accounts for high EC costs with regards to manufacturing tool costs, engineering rework, inventory obsolescence, and possible downstream EC propagation (Loch and Terwiesch 1999, Balakrishnan and Chakravarty 1996).

The objective of this research is to fully model the ECM process within a multi-project product development environment to provide insightful decision-making suggestions for companies regarding how engineering changes should be implemented with minimal adverse effects on normal NPD activities. To be more specific, this research intends to answer the following questions:

1. How important is ECM for a firm that is engaged in developing new products?

- What are the key contributors to the long lead times for NPD in relation with ECM? And vice versa.

- What are the key contributors to the low success rates for NPD in relation with ECM? And vice versa.

- What is the bottleneck activity in NPD process on which the impact of the occurrence is the most significant?

2. What is the optimal way of allocating limited resources between NPD and ECM?

The paper is organized as follows. In the next section, a brief review of literature with respect to the modeling method that previous research adopted is discussed. The methodology that this research will follow is then presented and justified. Section 3 presents the simulation model and the underlining assumptions. Results and decision-makng strategies based on observations are discussed in Section 4. In conclusion, limitations and possible extensions are listed in Section 5.

\section{METHODOLOGY}

Papers associated with analytical or computer modeling of ECM or NPD listed in the following table with a brief description of their purpose and primary model settings. Models are classified by three different types: mathematical model (analytical solution), concept framework, and computer simulation.

Table 1: Summary of methodology

\begin{tabular}{|c|c|c|}
\hline Reference & Purpose & Description \\
\hline \multicolumn{3}{|c|}{ Mathematical Methods } \\
\hline $\begin{array}{l}\text { Hegde, Sham } \\
\text { Kekre, and Sunder } \\
\text { Kekre } 1992\end{array}$ & $\begin{array}{l}\text { Statistical analysis to quantify the impact and interaction } \\
\text { of various time drivers for ECM. }\end{array}$ & $\begin{array}{l}\text { - Single/Multiple variable(s) regression } \\
\text { of idle time-in process (queue time) }\end{array}$ \\
\hline $\begin{array}{l}\text { Balakrishinan and } \\
\text { Chakravarty } 1996\end{array}$ & $\begin{array}{l}\text { An analytical optimization model to investigate the im- } \\
\text { pact of an EC on market opportunities and manufactur- } \\
\text { ing costs. }\end{array}$ & $\begin{array}{l}\text { - Linear programming } \\
\text { Objective function: } \\
\text { maximize revenues and minimize } \\
\text { total cost ( in terms of backorders, } \\
\text { subcontracts, inventory holding, and } \\
\text { obsolescence) }\end{array}$ \\
\hline Ho and Li 1997 & $\begin{array}{l}\text { An analytical procedure to compute progressive proba- } \\
\text { bilities of ECs. }\end{array}$ & $\begin{array}{l}\text { - Equation for calculating the progres- } \\
\text { sive probability of EC for each item } \\
\text { - Sensitive analysis }\end{array}$ \\
\hline $\begin{array}{l}\text { Krishnan, Eppinger, } \\
\text { and Whitney1997 }\end{array}$ & $\begin{array}{l}\text { A mathematical model of an overlapped NPD process } \\
\text { using evolution and sensitivity to identify overlapping } \\
\text { strategy for optimal product development performance. }\end{array}$ & $\begin{array}{l}\text { - Linear programming } \\
\text { Objective function: } \\
\text { minimize development lead time } \\
\lambda=t_{n}+d_{n}\end{array}$ \\
\hline $\begin{array}{l}\text { Barzizza, Caridi, } \\
\text { and Cigolini } 2001\end{array}$ & $\begin{array}{l}\text { A mathematical model aims at suggesting use-as-is } \\
\text { ECs' implementation at the best time, with the least im- } \\
\text { pact on firm costs. }\end{array}$ & $\begin{array}{l}\text { - Linear programming } \\
\text { - Objective function: } \\
\text { maximize total saving } S_{N} \text { resulting } \\
\text { from the production of } N \text { units of } \\
\text { pre-change product in place of post- } \\
\text { change product. }\end{array}$ \\
\hline
\end{tabular}


Table 1: Summary of methodology (continued)

\begin{tabular}{|c|c|c|}
\hline Reference & Purpose & Description \\
\hline \multicolumn{3}{|c|}{$\begin{array}{rr}\text { Concept Framework } \\
\end{array}$} \\
\hline $\begin{array}{l}\text { Krishnan, Eppinger, } \\
\text { and Whitney } 1997\end{array}$ & $\begin{array}{l}\text { An Evolution-Sensitivity framework to identify overlap- } \\
\text { ping strategy for optimal product development perfor- } \\
\text { mance under extreme values of evolution and sensitivity. }\end{array}$ & $\begin{array}{l}\text { - Applied when accurate data is not } \\
\text { available for mathematical model. } \\
\text { - Provides managerial insights using } \\
\text { qualitative evolution and sensitivity } \\
\text { inputs. }\end{array}$ \\
\hline $\begin{array}{l}\text { Browning, Fricke, } \\
\text { and Negele } 2006\end{array}$ & $\begin{array}{l}\text { A basic framework for modeling NPD process to support } \\
\text { a variety of purposes. }\end{array}$ & $\begin{array}{l}\text { - Two main objects: actions and inte- } \\
\text { ractions - i.e. activities and delive- } \\
\text { rables. } \\
\text { - Input-process-output (IPO) or sup- } \\
\text { plier-IPO-customer (SIPOC) repre- } \\
\text { sentations. } \\
\end{array}$ \\
\hline \multicolumn{3}{|c|}{ Computer Simulation } \\
\hline Но 1994 & $\begin{array}{l}\text { A simulation experiment to examine the effect of differ- } \\
\text { ent frequencies of ECs on the performance of multi-level } \\
\text { MRP system under various operating environment }\end{array}$ & $\begin{array}{l}\text { - Simulation experiment } \\
\text { - Analysis of variance (ANOVA) of } \\
\text { total cost and obsolescence cost }\end{array}$ \\
\hline $\begin{array}{l}\text { Bhuiyan, Gerwin, } \\
\text { and Thomson } 2004\end{array}$ & $\begin{array}{l}\text { A stochastic computer model to examine how the key } \\
\text { features of overlapping and functional interaction affect } \\
\text { the performance measures of development time and effort } \\
\text { under varying uncertainty conditions. }\end{array}$ & $\begin{array}{l}\text { - Discrete event simulation } \\
\text { - Process modeling } \\
\text { - Result analysis by the shape of } \\
\text { curves. }\end{array}$ \\
\hline $\begin{array}{l}\text { Cho and Eppinger } \\
2005\end{array}$ & $\begin{array}{l}\text { A process modeling and analysis technique for managing } \\
\text { complex design projects. }\end{array}$ & $\begin{array}{l}\text { - Information-based Design Structure } \\
\text { Matrix structuring analysis } \\
\text { - Network -based project scheduling } \\
\text { analysis } \\
\text { - Parallel discrete event simulation } \\
\end{array}$ \\
\hline $\begin{array}{l}\text { Bhuiyan and } \\
\text { Thomson } 2006\end{array}$ & $\begin{array}{l}\text { A stochastic computer model to compare the behavior of } \\
\text { two methods of managing an ECR process, individually } \\
\text { or in a batch. }\end{array}$ & $\begin{array}{l}\text { - Discrete event simulation } \\
\text { - Process modeling } \\
\text { - Process performance measurements: } \\
\text { development time and effort } \\
\end{array}$ \\
\hline
\end{tabular}

\subsection{Comparison of Major Approaches}

Formulating a mathematical model, which is to "represent a system in terms of logical and quantitative relationships that are then manipulated and changed to see how the model react, and thus how the system would react" (Law 2007), is one way to define and abstract the problem of interest. Among major algorithm approaches, linear programming, whose objective function and constraints are all linear functions, is "fit to solve the general problem of allocation limited resources among competing activities in the best possible way" (Hillier and Lieberman 2001).

Another reasonable representation that can be considered is the queueing theory since the time wasted by waiting in lines for limited resources is a major factor in both the long lead time and the low production rates of NPD and ECM. By applying appropriate queueing models using different types of probability distributions for inter-arrival and service times, average waiting time and number of entities in queue can be obtained to measure the performance of the queue.

To gain insights into the operation of a very complex and dynamic real world system without too much over simplification, computer simulation is a more effective and powerful tool than analytic mathematical modeling.

\subsection{Methodology Justification}

This research focuses on the "information flow" standpoint of an NPD process (Krishinan, Eppinger, and Whitney 1997). From this information processing point of view, an NPD project can be treated as evolving product information that travels through time (total development cycle time) and space (all the departments involved) till the final design solution, seizing and releasing engineering capacity. However, we are not interested in the way how the input information of an NPD activity 


\section{Li and Moon}

evolves gradually into the eventual output deliverable, but the separated points in time when entities arriving and leaving an NPD activity and the corresponding change of the state of system. By doing this, we can capture the duration of each NPD/ECM activity and utilization of resources from different departments as well.

Also, the repeatable nature of an NPD process structure provides validation for decomposing an NPD process into successive design and development phases, each enclosing several sequentially repeated activities. Nevertheless, NPD is also an iterative process rather than a purely linear one with unforeseen uncertainty and ambiguity (Terwiesch and Loch 1999). This feature can be represented by variations in both activity duration and NPD iteration.

\section{MODEL FRAMEWORK}

\subsection{NPD Framework}

The NPD model has three phases, namely Concept, Design, and Production. They occur sequentially but with certain degrees of overlapping. Each phase is consisted of three sequentially numbered activities to represent its different stages. Figure 1 illustrates this 3-phase and 3-activity NPD framework.

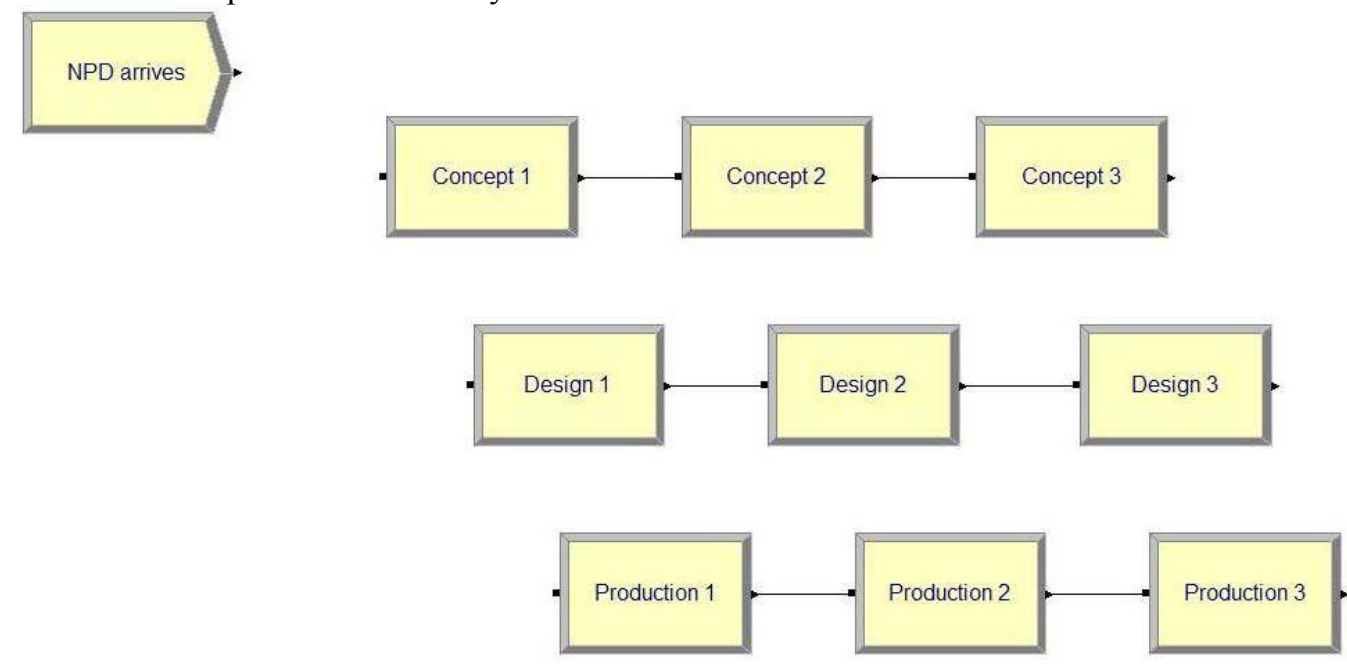

Figure 1: Three-phase \& three-activity NPD framework

\subsection{Size and Frequency of NPD}

Each NPD project begins with an inter-arrival value of 20 days, 48 days, or 120 days depending on project size and product type. The reasons why these values were chosen are 1) from high to low, they represent three specified rates of arrival; 2) the smallest number was set to be 20 so that companies that handle relatively simple but more frequent NPD projects start one NPD project each month while the largest number as 120 so that for the case of low arrival rate companies start more complex NPD projects half a year. Correspondingly, the arrival rate expressed in Arena is CONST 12(number of NPD projects)/yr, 5/yr, and 2/yr (Kelton, Sadawski, and Sturrock 2006). When NPD arrives at a lower rate, we assume the project to be more complicated and thus require more processing time to finish. The duration of an activity is set to be proportional to its arrival rate.

The activity duration is assumed to follow the normal distribution, which represents the uncertainties in product design and development processes. The mean value of activity duration within one phase remains the same, but increases as NPD entities proceed from one phase to another because of the increasing activity complexity since more product development tasks are involved. The sum of all the duration mean values ( 3 activities within 3 phases) for one entire NPD project is set to be equal to the inter-arrival value. This means that if everything is fixed without any uncertainty (i.e. there is no variation for activity duration and iteration), a company has the exact time to go through each NPD project without any overlapping. Detailed activity duration assignment is shown in Table 2. 


\section{Li and Moon}

Table 2: NPD Arrival Rates and Activity Duration

\begin{tabular}{|l|l|l|l|}
\hline \multirow{2}{*}{$\begin{array}{l}\text { NPD } \\
\text { Frequency }\end{array}$} & \multicolumn{3}{|c|}{ NPD Activity Duration in } \\
\cline { 2 - 4 } CONST 12/yr & NORM $(1.333,0.645)$ & NORM $(2,0.791)$ & PORM $(3.333,1.021)$ \\
\hline CONST 5/yr & NORM $(3.2,1)$ & NORM $(4.8,1.225)$ & $\operatorname{NORM~}(8,1.581)$ \\
\hline CONST 2/yr & NORM $(8,1.581)$ & NORM $(12,1.936)$ & $\operatorname{NORM~}(20,2.5)$ \\
\hline
\end{tabular}

\subsection{Overlapping}

We refer to overlapping as the partial or full parallel execution of tasks. By having this 3-phase and 3-activity framework, we are able to construct an NPD process with $0 \%$ (sequential), 33\%, or $66 \%$ overlapping, while any amount between 0 and $100 \%$ can be true in real life. The NPD process with $0 \%$ overlapping is also called a sequential NPD process. NPD process with $33 \%$ overlapping is the one with the first activity of the following phase starts simultaneously with the third activity of the proceeding phase. For NPD process with $66 \%$ overlapping that is shown in Figure 2, the first activity of the following phase starts simultaneously with the second activity of the proceeding phase.

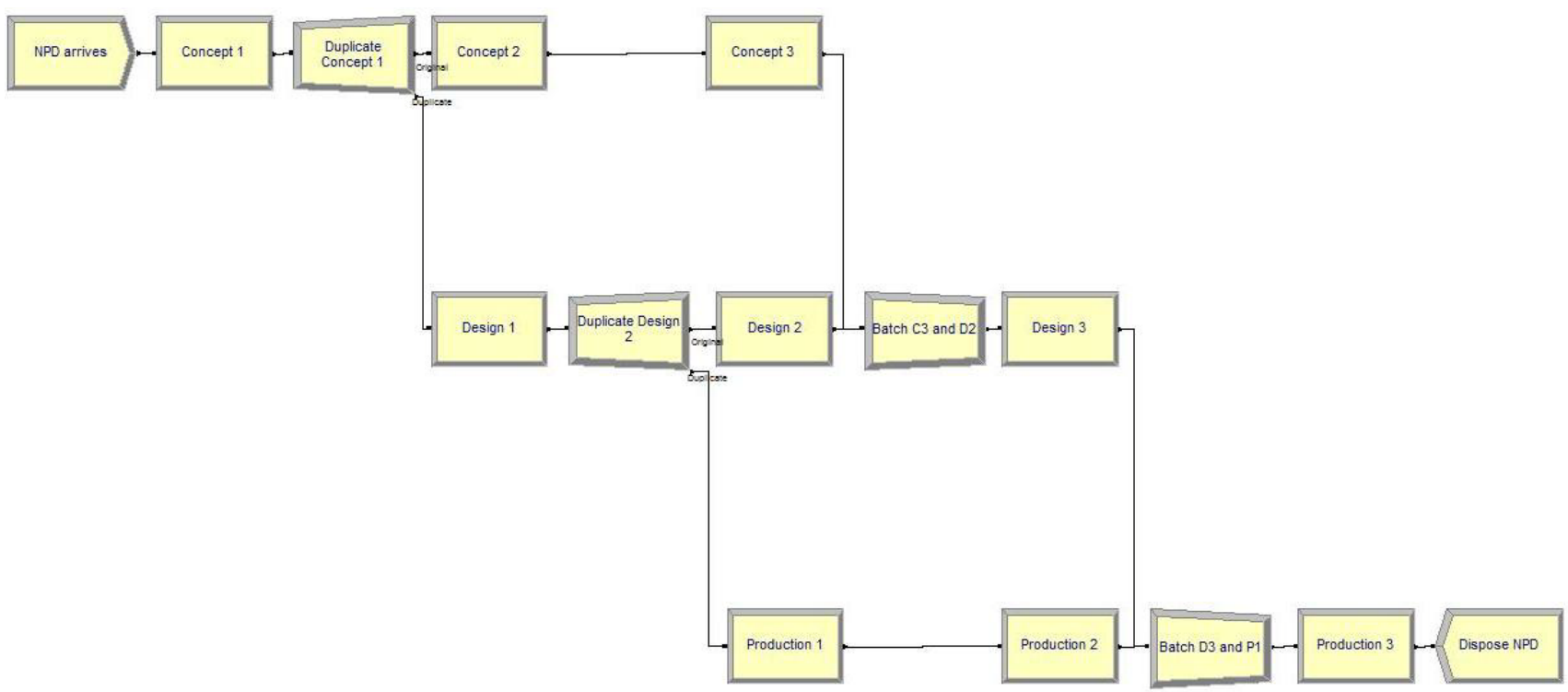

Figure 2: NPD process with $66 \%$ overlapping

\subsection{Departmental Interaction}

The concept of cross-functional integration among different functional areas during an NPD process is defined as departmental interaction. One of the three departments - Marketing, Design, and Manufacturing - takes major responsibility for a phase of its own specialization, and is called major department during that phase. In other words, Marketing Department is the major department in Concept phase, Design Department in Design phase, and Manufacturing Department in Production phase. However, the other two departments, defined as minor departments, also participate in the same phase with less resource requirements.

Two levels of departmental interaction, 60 (major dept.) - 20 (minor dept.) - 20 (minor dept.), and 40 (major dept.) - 30 (minor dept.) - 30 (minor dept.), are examined in our model. These two levels represent low and high departmental interaction with a total resource consumption of 100 number of resources.

\subsection{Iteration}

After each activity, there is a decision point in which NPD entities either pass through or go back by pre-assigned probability. NPD entities may go back and repeat the just-finished activity or any one of its previous activities, including activities in other phases. This rework process is called NPD iteration and is shown by Figure 3. If the new product information goes through the decision point after one activity, it means that the deliverable of this activity is a qualified input to the next. However, this does not guarantee that it won't cause any NPD iteration in downstream activities. Probability of the N-way deci- 


\section{Li and Moon}

sion by chance to go back to one certain activity for rework is also modeled. (See Appendix A for additional model parameters).

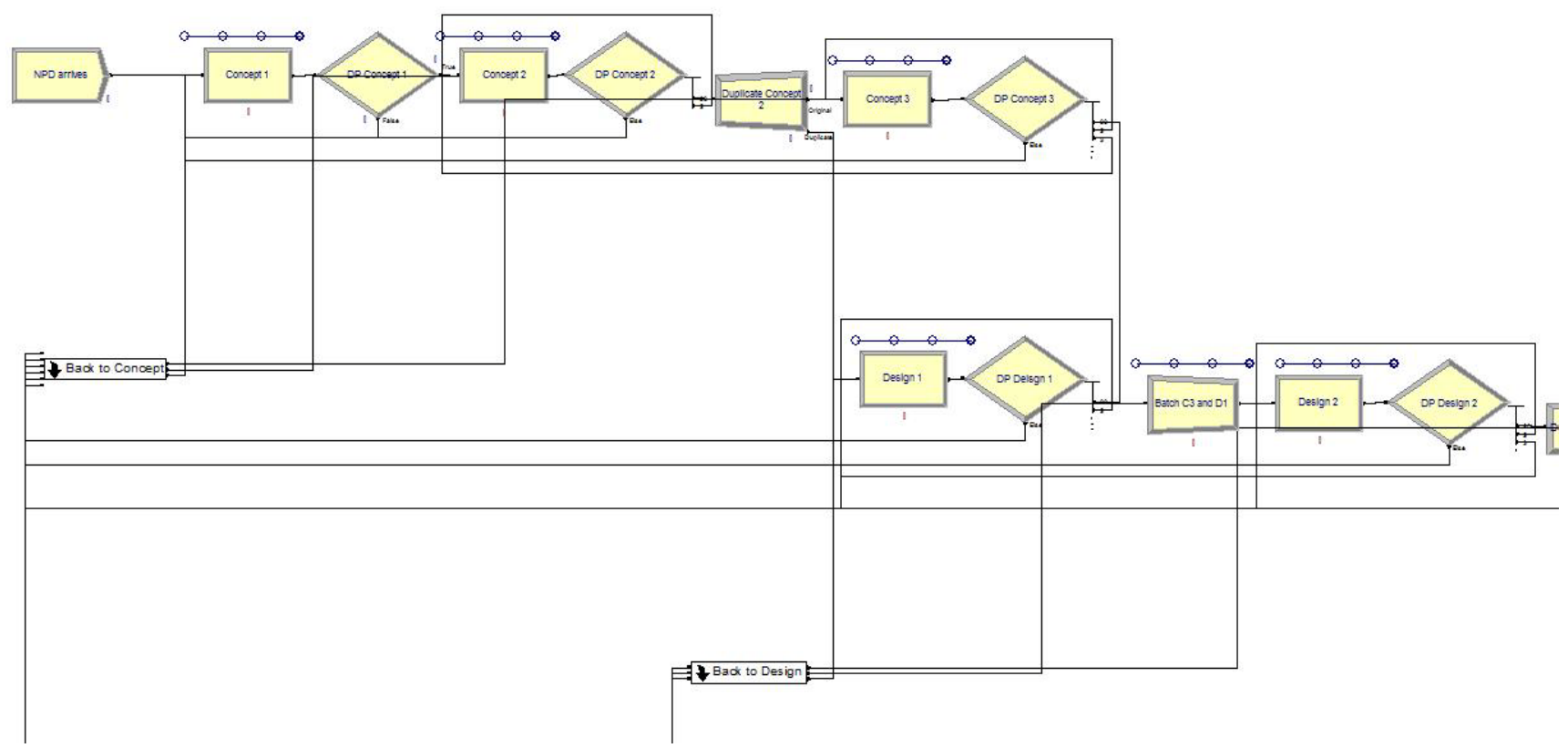

Figure 3: Model overview of NPD with overlapping and iteration

\subsection{ECM Framework}

One EC is assumed to be confined in only one NPD activity in this model. Concept 3, three activities in Design, and three activities in Production each have an equal chance of implementing an EC. Changes that are undertaken in Concept 1 and Concept 2 are not considered as ECs since within the first two NPD activities a comprehensively large number of new product ideas are gathered, discussed and modified. Thus NPD ideas are less formally organized. Figure 4 is the model overview of the ECM part.

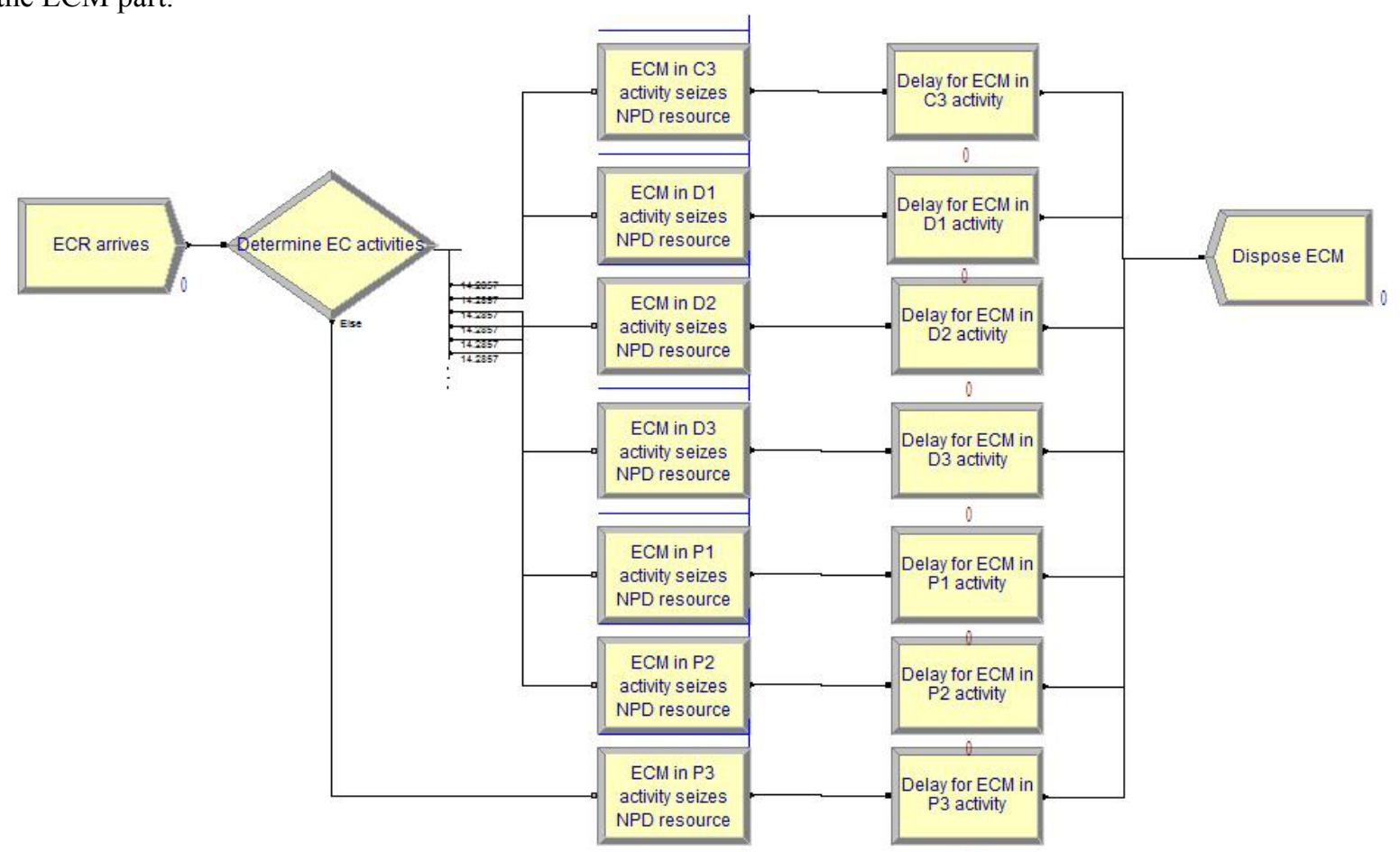

Figure 4: Model overview of ECM 


\subsection{Size and Frequency of ECM}

Compared with NPDs that are more likely sticking to a planned schedule, ECRs occur without plans. So we use exponential distribution to assume ECRs' arrival. The ECM process time is set to be proportional to its corresponding arrival rate. It follows the triangular distribution, where there is a most-likely time with some variation on two sides, represented by the most likely, minimum, and maximum values respectively. It also increases proportionally from phase to phase in the same fashion as NPD activity duration does. Table 3 shows the detailed process time for an EC to be carried out within different NPD phases at three arrival rates.

Table 3: ECM Arrival Rates and Activity Duration

\begin{tabular}{|c|c|c|c|}
\hline \multirow{2}{*}{$\begin{array}{l}\text { ECM } \\
\text { Arrival Rate }\end{array}$} & \multicolumn{3}{|c|}{ ECM Process Time in } \\
\hline & Concept phase & Design phase & Production phase \\
\hline Random (EXPO) 8/mo & TRIA $(0.25,0.5,0.75)$ & TRIA $(0.38,0.75,1.12)$ & TRIA $(0.62,1.25,1.88)$ \\
\hline Random (EXPO) 4/mo & TRIA $(0.5,1,1.5)$ & TRIA $(0.75,1.5,2.25)$ & TRIA $(1.25,2.5,3.75)$ \\
\hline Random (EXPO) 2/mo & TRIA $(1,2,3)$ & TRIA $(1.5,3,4.5)$ & TRIA $(2.5,5,7.5)$ \\
\hline
\end{tabular}

\subsection{ECM Effort}

The amount of resources required for an EC to be processed is called ECM effort. Three levels of ECM effort, 2-2-2, 5-5-5 and 10-10-10, are examined in this model. We assume that an EC consumes equal number of resources from all three departments no matter in which phase it occurs.

\subsection{Resource Using Priority}

Resources can represent staffs, computer/machine, documentation support, or any other individual server. In our model, we examined three levels resources, that is, 200, 100, or 60 numbers of resources from each department. We set the minimum number to be 60 resources per department, which is equal to the resource consumption for a major department at low level of departmental interaction, in order to ensure that the major department gets enough resource to let NPD process flow. We assume that each resource is qualified to handle all the NPD activities in three phases. When there are not enough resources available for both processes, a priority need to be assigned to either NPD or ECM to get necessary resource first.

\subsection{Running Parameters}

We've specified the running parameters Hours-Per-Day as 8 and Work-Day-Per-Year to be 20 days/month * 12 months/year (240 days/year). And the model is run in ten replications with a replication length of 2 years.

\section{PRELIMINARY RESULTS}

\subsection{Mathematical Expressions in Text and in Displays}

For the model described above, we analyzed the influence of resource constraint, resource using priority, overlapping, NPD departmental interaction, ECM effort, on both NPD and ECM lead time and productivity under different NPD and ECM arrival rates. Three levels of NPD and ECM arrival rates are combined in pairs according to their value. That is, high NPD arrival rate is studied with high ECM arrival rate, and low NPD arrival rate with low ECM arrival rate.

Two main model performance measures, productivity and lead time, are evaluated using a separate application PAN (Process Analyzer). Productivity is defined as the proportion of NPD/ECM entities that complete their development activities and leave the system through the simulation duration (Number In/Number Out). And lead time is the total time a successful NPD/ECM entity being processed. This is the time that elapsed between an entity's arrival and its departure (sum of the waiting time in queue and the development time at corresponding departments).

Only partial results are presented in this paper due to space limitation. The following two charts show the impacts of overlapping, NPD departmental interaction, and ECM effort on NPD Total Time and Productivity under resource constraint of 60 units from each department. 


\section{Li and Moon}

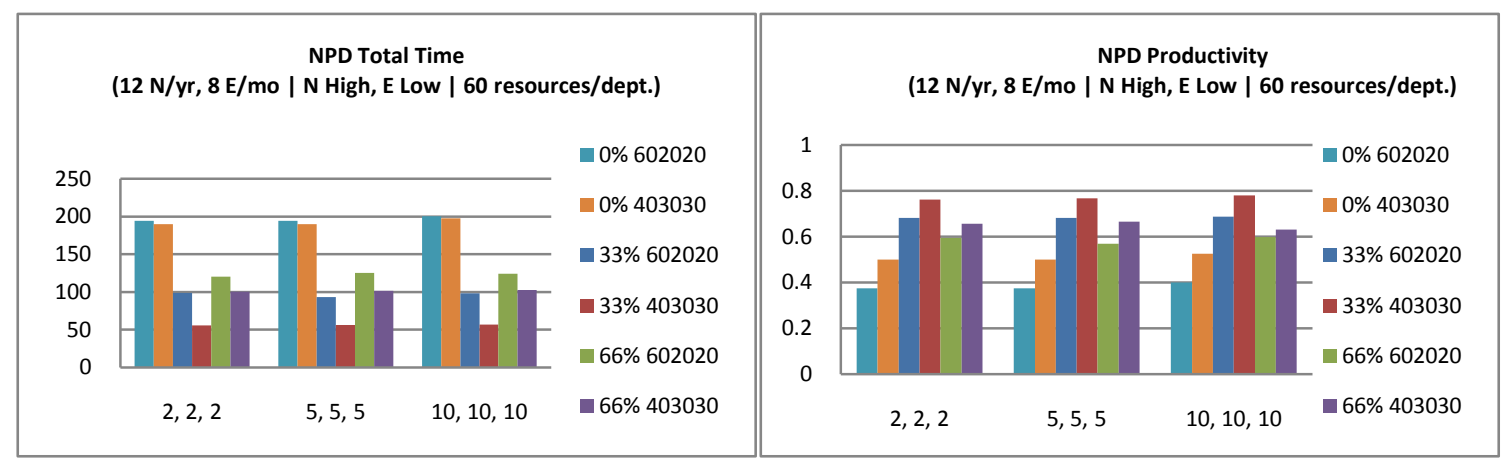

\subsection{Observation and Explanation}

Based on the results we obtained, several observations are made and its possible explanations are given:

\begin{tabular}{|c|c|}
\hline Observation & Explanation \\
\hline $\begin{array}{l}\text { When there are unlimited resources ( } 200 \text { re- } \\
\text { sources/dept. in this case) for NPD and ECM activi- } \\
\text { ties, higher degree of overlapping results in the re- } \\
\text { duction of NPD lead time. }\end{array}$ & $\begin{array}{l}\text { With more amount of overlapping, there will be more product devel- } \\
\text { opment activities executed before the completion of the previous } \\
\text { ones. So products are developed faster if there are enough resources } \\
\text { available. }\end{array}$ \\
\hline $\begin{array}{l}\text { When there are not enough resources ( } 60 \text { re- } \\
\text { sources/dept. in this case) for NPD and ECM activi- } \\
\text { ties, overlapping as much as possible is no longer } \\
\text { recommended. }\end{array}$ & $\begin{array}{l}\text { If only limited resources are given, a medium level of overlapping and } \\
\text { high departmental interaction yields the optimal NPD lead time. Firms } \\
\text { need to make compromise between shorter value-added time but } \\
\text { longer wait time to grab resources under higher degree of overlapping. }\end{array}$ \\
\hline $\begin{array}{l}\text { As the Number of Resources decreases, Productivity } \\
\text { of both NPD and ECM drops off, but NPD with a } \\
\text { higher rate. }\end{array}$ & $\begin{array}{l}\text { This phenomenon is pretty straightforward. When there are fewer re- } \\
\text { sources available, the resource utilization raises, sometimes even gets } \\
\text { close to } 100 \% \text {. Then fewer NPDs and ECMs will have enough re- } \\
\text { sources to be completed in a certain time period, runtime in this case. }\end{array}$ \\
\hline $\begin{array}{l}\text { As the Number of Resources decreases, Lead Time } \\
\text { of both NPD and ECM goes up. }\end{array}$ & $\begin{array}{l}\text { Even for those NPDs and ECMs that get required resources to be } \\
\text { processed, the total time (time an entity enters the system until it ex- } \\
\text { its) will be longer due to longer wait time for fewer resources that are } \\
\text { available. }\end{array}$ \\
\hline $\begin{array}{l}\text { A high departmental interaction level results in } \\
\text { higher productivity and shorter lead time than a low } \\
\text { departmental interaction level, especially when re- } \\
\text { sources are limited. }\end{array}$ & $\begin{array}{l}\text { Because each incoming ECM may consume resources from the three } \\
\text { departments with equal chance. With a total resource demand un- } \\
\text { changed, if there is more departmental interaction, there will be more } \\
\text { spare resources for the major department to execute. }\end{array}$ \\
\hline $\begin{array}{l}\text { The Priority assigned to NPD and ECM matters on- } \\
\text { ly when the resources are limited and the organiza- } \\
\text { tion choose to pursue a low level of departmental } \\
\text { interaction ( } 60-20-20 \text { in this paper). } \\
\text { When high priority is assigned to NPD, productivity } \\
\text { of NPD is about } 50 \% \text { higher than the situation in } \\
\text { which high priority is given to ECM, while the } \\
\text { productivity of ECM is just slightly lower. But at } \\
\text { the same time, both NPD and ECM take longer to } \\
\text { complete. }\end{array}$ & $\begin{array}{l}\text { By assigning higher priority to NPD, there are more NPD entities } \\
\text { coming out of the system without affecting ECM productivity much. } \\
\text { However, the price to pay is the longer lead time for both NPD and } \\
\text { ECM since there are more resource demands thus resulting in a higher } \\
\text { overall resource utilization. Organizations face tradeoffs between } \\
\text { productivity and lead time in this situation. }\end{array}$ \\
\hline $\begin{array}{l}\text { The } E C M \text { Effort is not the key factor of NPD/ECM } \\
\text { Productivity. It affects NPD/ECM lead time only } \\
\text { when the resources are limited and the organization } \\
\text { choose to pursue a high level of departmental inte- } \\
\text { raction (40-30-30 in this paper). }\end{array}$ & $\begin{array}{l}\text { Recall that high level of departmental interaction means that minor } \\
\text { departments participate more while major department allocates fewer } \\
\text { resources in its own specialization phase. So if an ECM is complex } \\
\text { and requires greater effort ( } 10 \text { resources from each department in this } \\
\text { case), minor departments are much easier to be out of resources than } \\
\text { in the low departmental interaction case. }\end{array}$ \\
\hline
\end{tabular}




\section{Li and Moon}

\subsection{Conclusion}

The NPD and ECM model framework introduced above address several issues that previous research hasn't. In this model, we capture important new product design and development characteristics such as iteration and overlapping of NPD process, interaction among different functional areas, resource constraints and its using priority. We also take into account the size of NPD projects and ECRs in terms of their arrival rates and processing effort. From the simulation results, a number of conclusions can be drawn:

1) ECM is an important aspect to the success of an NPD project. On one hand, it solves safety or critical functionality problems of a product and it reflects customer requirements or technology developments. On the other hand, it also consumes a considerable amount of product development resources which in turn affects the lead time and productivity of regular NPD activities significantly.

2) While each of the six model variables, overlapping, NPD departmental interaction, ECM effort, resource constraints, arrival rate, and resource using priority, affects the overall lead time and productivity of both NPD and ECM by some extent, the effect of resource constraints is most significant.

3) As stated in Section 4, this model addresses decision-making suggestions for firms under different organization environment and resource constraint condition. Specifically, when the resources are limited, a medium level of overlapping and high departmental interaction is suggested to optimize system resource utilization.

\section{FUTURE WORK}

\subsection{Verification and Validation}

Verification is defined by Law (2007) as determining whether the "assumptions documents" has been correctly translated into "computer program", i.e., debugging the simulation computer program. Methods considered in this research include:

1) Run the model under simplifying assumptions for which its true characteristics are known, and then gradually add details into the simulation project.

2) Run the model under a variety of settings of the input parameters, especially in those extreme conditions, and check to see if the output is reasonable.

3) Use animation to enhance the credibility of this model.

Validation is the process of determining whether a simulation model is an accurate representation of the system, for the particular objectives of the study (Law 2007). In this research, model validation will include the following steps:

1) Use output analysis as the first step of model validation, and check to see if the simulation output is reasonable.

2) Comparison of this model and related studies provides another way of validation.

3) Apply the correlated inspection approach. That is, compare real-world observation and simulation output with historical system input data. For example, given input parameter from industry (actual observed inter-arrival time of NPD projects and EC Requests; actual observed activity duration in different NPD phases; etc.), we can determine the accuracy of the model by comparing the model output data and the inspection from company.

\subsection{Experimental Design}

From the preliminary running of the first model version, we have already got some ideas about which model variables, such as inter-arrival rates of NPD and ECM, NPD departmental interaction, ECM effort, are likely to be important. However, carefully designed experiments should be carried out for efficient experimentation in determining which factors are most important and joint effect of the factors on a response as well. Table 4 shows possible model factors and responses.

Table 4: Model factors and responses

\begin{tabular}{|lll|l|}
\hline Possible Factors & $\begin{array}{l}\text { Quantitative } \\
\text { Qualitative? }\end{array}$ & $\begin{array}{l}\text { Controllable or } \\
\text { Uncontrollable? }\end{array}$ & Possible Responses \\
\hline Overlapping & Quantitative & Controllable & NPD/ECM Lead Time \\
NPD Department Interaction & Quantitative & Controllable & Duration of NPD Activity \\
ECM Effort & Quantitative & Controllable & Production Rate \\
Number of Resources & Quantitative & Controllable & Average Delay \\
NPD Inter-arrival Rate & Quantitative & Uncontrollable & Resource Utilization \\
ECM Inter-arrival Rate & Quantitative & Uncontrollable & Cost \\
Resource Using Priority & Qualitative & Controllable & Customer Satisfaction \\
NPD/ECM Cancellation Policy & Qualitative & Controllable & \\
\hline
\end{tabular}




\subsection{Data Collection}

The parameter setting and input data for this model are hypotheses based on relevant results from similar studies or the modeler's experience. These may be obsolete due to time concerns but still realistic when this simulation study is initiated. We will improve them or may even replace them by real inspection from industry in later stages of this research.

\subsection{Model Extension}

This model is a first step toward further investigations. There are several aspects of this model that need further research.

- The assumption that one EC is confined in one NPD activity is not always true. An EC that requires a rework in a design activity may propagate to other activities in design or production phase. Future study should include engineering change propagation as one feature of the ECM process.

- In the current model, probabilities for feedback iterations are assigned to an NPD project. However, when a new product project needs to go back to earlier NPD activities for a rework, subsequent activities need to be followed again no matter how many times these activities are repeated. In other words, an NPD entity has to go through again all the downstream activities after being sent back to the iteration starting point. Feed-forward flexibility and learning effects for iteration need to be considered in future work.

- In this model, it is assumed that NPD and ECM share the same pool of resources with using priority. Different models could let NPD and ECM have their own dedicated resources. Alternatively, NPD and ECM still use the same pool of resources. But ECM requests for outsourcing when resources are not available. In this case, different utility costs can be set for using resources within a department, cross departments, and for outsourcing.

- Besides lead time and productivity, other critical criteria such as resource utilization, total cost, and customer satisfaction, can be adopted to review and evaluate the impact of ECM throughout NPD process.

- As we can see from the preliminary results of the first version of model, productivity of NPD and ECM keeps to be less than $100 \%$ and is far less when the resource level is low (with a number of 60 per department). Black and Repenning report that the policy cancellation of the work that falls behind schedule well in advance of its launch date can ensure consistently high performance and recovering productive capability (Black and Repenning 2001). Effective cancellation of incomplete NPD/ECM is also a possible direction of further research.

APPENDIX PROBABILITY OF N-WAY BY CHANCE DECISION FOR NPD ITERATION

\begin{tabular}{|l|l|c|}
\hline $\begin{array}{c}\text { Decision } \\
\text { Point after }\end{array}$ & Next Proceeding Activity & Probability \\
\hline Concept 1 & Concept 2 & $\mathbf{9 5}$ \\
\hline & Concept 1 & $\mathbf{5}$ \\
\hline Concept 2 & Concept 3 & $\mathbf{9 0}$ \\
\hline & Concept 2 & $\mathbf{5}$ \\
\hline & Concept 1 & $\mathbf{5}$ \\
\hline Concept 3 & Design 1 & $\mathbf{9 0}$ \\
\hline & Concept 3 & $\mathbf{5}$ \\
\hline & Concept 2 & $\mathbf{3}$ \\
\hline & Concept 1 & $\mathbf{9 0}$ \\
\hline Design 1 & Design 2 & $\mathbf{5}$ \\
\hline & Design 1 & $\mathbf{5}$ \\
\hline & BACK TO CONCEPT \\
\hline Design 2 & Design 3 & $\mathbf{9 0}$ \\
\hline & Design 2 & $\mathbf{3}$ \\
\hline & Design 1 & $\mathbf{2}$ \\
\hline & BACK TO CONCEPT & $\mathbf{9 0}$ \\
\hline Design 3 & Production 1 & $\mathbf{5}$ \\
\hline & Design 3 & $\mathbf{2}$ \\
\hline & Design 2 & $\mathbf{1}$ \\
\hline & Design 1 \\
\hline & BACK TO CONCEPT & $\mathbf{2}$ \\
\hline
\end{tabular}

\begin{tabular}{|l|l|c|}
\hline $\begin{array}{c}\text { Decision } \\
\text { Point after }\end{array}$ & Next Proceeding Activity & Probability \\
\hline Production 2 & Production 3 & $\mathbf{9 0}$ \\
\hline & Production 2 & $\mathbf{5}$ \\
\hline & Production 1 & $\mathbf{2}$ \\
\hline & BACK TO DESIGN & $\mathbf{2}$ \\
\hline & BACK TO CONCEPT & $\mathbf{1}$ \\
\hline Production 3 & NPD Complete & $\mathbf{9 0}$ \\
\hline & Production 3 & $\mathbf{5}$ \\
\hline & Production 2 & $\mathbf{2}$ \\
\hline & Production 1 & $\mathbf{1}$ \\
\hline & BACK TO DESIGN & $\mathbf{1}$ \\
\hline & BACK TO CONCEPT & $\mathbf{1}$ \\
\hline \multicolumn{1}{||}{ BACK TO CONCEPT PHASE } \\
\hline Next Proceeding Activity & Probability \\
\hline Concept 3 & $\mathbf{5 0}$ \\
\hline Concept 2 & $\mathbf{3 0}$ \\
\hline Concept 1 & $\mathbf{2 0}$ \\
\hline \multicolumn{2}{|l|}{ BACK TO DESIGN PHASE } \\
\hline Next Proceeding Activity & Probability \\
\hline Design 3 & $\mathbf{5 0}$ \\
\hline
\end{tabular}




\begin{tabular}{|l|l|c|}
\hline Production 1 & Production 2 & $\mathbf{9 0}$ \\
\hline & Production 1 & $\mathbf{5}$ \\
\hline & BACK TO DESIGN & $\mathbf{4}$ \\
\hline & BACK TO CONCEPT & $\mathbf{1}$ \\
\hline
\end{tabular}

\begin{tabular}{|l|l|}
\hline Design 2 & $\mathbf{3 0}$ \\
\hline Design 1 & $\mathbf{2 0}$ \\
\hline
\end{tabular}

\section{REFERENCES}

Balakrishnan, N., and A. K. Chakravarty. 1996. Managing Engineering Change: Market Opportunities and Manufacturing Costs. Production and Operations Management. 5 (4):335-356.

Barzizza, R., M. Caridi, and R. Cigolini. 2001. Engineering Change: A Theoretical Assessment and A Case Study. Production Planning \& Control. 12 (7):717-726.

Bhuiyan, N., D. Gerwin, and V. Thomson. 2004. Simulation of the New Product Development Process for Performance Improvement. Management Science. 50(12):1690-1703.

Bhuiyan, N., G. Gr, and V. Thomson. 2006. Engineering Change Request Management in a New Product Development Process. European Journal of Innovation Management. 9(1):5-19.

Black, L. J., and N. P. Repenning, 2001. Why Firefighting Is Never Enough: Preserving High-Quality Product Development. System Dynamic Review. 17(1):33-62.

Browning, T. R., E. Fricke, and H. Negele. 2006. Key Concepts in Modeling Product Development Processes. System Engineering. 9(2):104-128.

Browning, T. R., and R. V. Ramasesh. 2007. A Survey of Activity Network-Based Process Models for Managing Product Development Projects. J. Product Innovation Management. 16(2):160-172.

Cho, S. H., and S. D. Eppinger. 2005. A Simulation-Based Process Model for Managing Complex Design Projects. IEEE Transactions on Engineering Management. 52(3):316-328.

Hegde, G. G., Sham Kekre, and Sunder Kekre. 1992. Engineering Changes and Time Delays: A Field Investigation. International Journal of Production Economics. 28(3):341-352.

Ho, C. J. 1994. Evaluating the Impact of Frequent Engineering Changes on MRP System Performance. International Journal of Production Research. 32(3):619-641.

Ho, C. J., and J. Li. 1997. Progressive Engineering Changes in Multi-level Product Structures. Omega: International Journal for Management Science. 25(5):585-594.

Krishnan, V., S. D. Eppinger, and D. E. Whitney. 1997. A Model-Based Framework to Overlap Product Development Activities. Management Science. 43(4):437-451.

Loch, C. H., and C. Terwiesch. 1999. Accelerating the Process of Engineering Change Orders: Capacity and Congestion Effects. J. Product Innovation Management. 16(2):145-159.

Terwiesch, C., and C. H. Loch. 1999. Managing the Process of Engineering Change Orders: The Case of the Climate Control System in Automobile Development. J. Product Innovation Management. 16(2):160-172.

Hillier, F. S., and G. J. Lieberman. 2001. Simulation Modeling \& Analysis. 4th ed. New York: McGraw-Hill, Inc.

Kelton, W. David, R. P. Sadowski, and D. T. Sturrock. 2006. Simulation with Arena. 4th ed. London: McGraw-Hill, Inc.

Law, A. M. 2007. Simulation Modeling \& Analysis. 4th ed. New York: McGraw-Hill, Inc.

\section{AUTHOR BIOGRAPHIES}

WEILIN LI is a Ph.D. candidate in the Department of Mechanical and Aerospace Engineering at Syracuse University, USA. She received the B.S. Degree in Mechanical Engineering and Automation from the School of Mechanical and Power Energy Engineering at Shanghai Jiao Tong University, China. Her research focuses on modeling and simulation of complex product design and development process, engineering change management, and process improvement to product realization. Her email is <wli12esyr.edu>.

YOUNG B. MOON is on the Faculty of Mechanical and Aerospace Engineering at Syracuse University, USA. He is the Director of the Institute for Manufacturing Enterprises. He holds a PhD degree from Purdue University, USA and is a Professional Engineer (PE), a Certified Fellow in Production and Inventory Management (CFPIM) and a Certified Manufacturing Engineer $(\mathrm{CMfgE})$. His professional interests include enterprise systems, product realization processes and systems, product life cycle management, and modeling and simulation. His email address is <ybmoonesyr.edu>. 